\title{
Conocimiento histórico y niños pequeños: parques infantiles y escuela municipal de educación infantil ${ }^{1}$
}

Marcia Aparecida Gobbi ${ }^{2}$

Universidade de São Paulo, Brasil.

mgobbi@usp.br

1 Artículo publicado originalmente en Educação em Revista, 28(2), 203-224. Agradecemos la autorización brindada para su traducción.

2 Doutora em Ciencias Sociais e Educação pela Universidade Estadual de Campinas (UNICAMP); Professora da Faculdade de Educação da Universidade de São Paulo (USP). 
Traducciones

\title{
Conocimiento histórico y niños pequeños: parques infantiles y escuela municipal de educación infantil
}

\section{Resumen}

Este artículo relata la experiencia en el proyecto Los parques infantiles de Mario de Andrade ayer y hoy, emprendido por todos los profesionales y niños de una escuela municipal de Educación Infantil de la ciudad de Sao Paulo. La preocupación respecto al conocimiento histórico y los niños enla primera infancia y sus necesidades, desde una perspectiva no-escolarizadora y no anticipadora de la Enseñanza Fundamental, fue la tónica de esta investigación y un desafío. Busca aliar historia y memoria, estableciendo las relaciones entre Historia de la Educación, historia de la escolarización de niños pequeños y formación docente.

Palabras clave: Educación infantil, parques infantiles, conocimiento histórico.

\section{Historical knowledge and small children: children's playgrounds and the state's primary education}

\begin{abstract}
This article discusses an experience with the project "The children's playgrounds of Mario de Andrade, yesterday and today", undertaken by all the professionals and children of a state primary school in the city of São Paulo. The concern with historical knowledge and the children in the first years of primary school, with their specific qualities, their un-schooled perspective and their inability to predict the school's teaching approach, was the keynote of this study and the challenge faced. A link between history and memory is sought, establishing a relationship between the History of Education, the history of small children being schooled and teacher training.
\end{abstract}

Keywords: Early Childhood Education; Playgrounds; Historical Knowledge 


\section{Primera infancia e historia}

- ¿Qué están haciendo esos niños ahí en el parque? Hace mucho tiempo que están juntos, escarbando esa tierra.

- Profesora, ¡mira lo que encontré!

- Tráelo aquí para ver.

- Pero son pedazos de baldosas que están enterrados en el suelo. ¿Por qué tantos? ¿Pero qué van a hacer con eso?

Hace pocos años, en el barrio Lapa de Baixo, cercano a la estación de tren de Lapa, en la zona oeste de la ciudad de Sao Paulo, algunos niños que asisten a la Escuela Municipal de Educación InfantilNeydeGuzzi de Chiacchio ${ }^{3}$, en sus constantes juegos en el parque que pertenece a la escuela, encontraron pequeños fragmentos de baldosas blancas. Tal descubrimiento, un tanto inusitado, suscitó la curiosidad de las profesoras y de los demás funcionarios que trabajaban en la EMEI y de otros niños que hasta entonces se encontraban haciendo diferentes quehaceres, absortos en sus juegos.

El descubrimiento de los pedacitos de baldosa, enterradas en esta escuela de Educación Infantil del municipio de Sao Paulo, podría no haber llamado la atención de nadie más. Tantos son los acontecimientos en el día a día de la educación de la primera infancia, en diversos municipios del país, que este acontecimiento podría ser entendido como otra eventualidad para despertar el deseo de los niños de ver y oír algo insólito, solamente por un pequeño espacio de tiempo. Los alumnos posteriormente se irían a realizar otras actividades eincluso podría ser la profesora quien pusiera el asunto en el olvido: "dejemos todo y vámonos para el aula de clases".

Sin embargo, estos pequeños fragmentos de baldosas blancos, despertaron la atención en laespecie de excavación hecha por los niñas y niñas, de entre tres y seis años, en una tarde de abril de 2005, en la escuela pública municipal frecuentada, en su mayoría, por niños oriundos de barrios lejos del lugar donde está ubicada la escuela.Estos pedazos de baldosas, de diferentes tamaños y bastante desgastados por el tiempo, comenzaron a llamarla atención cuando se notó que había muchos y muchos más, lo que despertó la necesidad de hacer otras actividades entre los niños: reunión

3 Las Escuelas Municipales de Educación Infantil de São Paulo son comunmente conocidas con la sigla EMEI, que será utilizada por mí en este artículo. Las EMEls son destinadas a la educación y al cuidado de niños entre tres y cincos años de edad, ya que a los seis, actualmente, comienzan a asistir a escuelas de nivel fundamental. Agradezco especialmente a la directora y a las profesoras de la EMEI, Mayra Galatti Ozzetti. 
de pedacitos que se convertían en bichos, muñequitas, colocados en secuencia, delineaban pistas por donde pasaban los carritos, guiaban el agua que corría como en un río, en fin, un amplio y aparentemente inagotable ejercicio de invención infantil.

Entre los adultos, se evocaba el deseo de conocer a profundidad lo que estaba sucediendo - día tras día, aquellos pedacitos se multiplicaban en las manos de los niños y las niñas-, todo estoresultó en un movimiento entre los niños, que además de provocar su curiosidad, presentaba evidencias de un espacio diferente, ocupado en otro tiempo, tal vez, de forma diferente a lo que hoy es. Algunas de las profesoras ya conocían aspectos históricos del lugar donde trabajaban, lo que favoreció un previo establecimiento de las relaciones sobre el origen de los pequeños pedazos de baldosas concentrados en el área exterior. Los oídos y los ojos más atentos notaron, por otro lado, el interés de los descubridores en su excavación, una especie de actividad de arqueólogos encontrando astillas provenientes de un tiempo remoto, para cultivar curiosidades. La curiosidad sobre el mundo es una de las capacidades humanas más importantes, ella nos coloca al frente, nos hace andar, mover, permite la creación de proyectos y la materialización de los mismos, perturba aquello que tenemos naturalizado por la cotidianidad, que, a veces, sofoca, nos saca el brillo y el deseo. Curiosidades infantiles, en resonancia con las personas adultas, también en expansión inventiva por el mundo, pueden contribuir ala creación de grandes y provechosos momentos de investigación, en los cuales todos son considerados en el camino a seguir: adultos y niños.

Y fue así, - en el descubrimiento de pedazos de baldosas, enun parque público de una unidad escolar destinada a la primera infancia, -que tuvo inicio, por parte de todo el cuerpo docente de la escuela, un intenso trabajo preocupado por el conocimiento histórico y la relación tan delicada con los niños pequeños, para los cuales la enseñanza de la historia no se ha desarrollado de manera profunda, como requieren las investigaciones centradas en esta edad. Según Bittencourt (2007), muchas veces prevalece la afirmaciónde que es difícil la realización de un trabajo cengtrado en el conocimiento histórico en los niños pequeños, debido a su incapacidad de comprensión de los contenidos y a una incapacidad de abstracción, lo que imposibilitaría la comprensión del tiempo histórico. Prevalece, muchas veces, una idea de enseñanza de la historia que objetiva la memorización de conceptos o hechos históricos, ignorándo el camino por el que los niños pasarán, cuando vivan diferentes experiencias.

Retomaré este asunto más adelante, pero subrayo desde ahora, que no se trata de afirmar la imposibilidad de trabajos en la educación de la primera infancia que tengan en cuenta los estudios historiográficos, periodo de edad en el que también es pertinente la preocupación de los investigadores centrados en la enseñanza de la historia. Cabe mencionar, que en este rango de edad, aunque podamos trabajar con la noción de tiempo y conocimiento histórico, las expectativas en relación a los 
resultados sufren variaciones. Así como no tenemos una enseñanza sistematizada, basada en principios propios de la enseñanzafundamental, hay características especiales de esta etapa de la vida que obligatoriamente tienen que ser consideradas: el cuerpo necesita correr mientras dialoga con los compañeros o escucha a la profesora, resistiendo a un modelo escolar que le impone sentarse horas seguidas; la imaginación y la fantasía que llevan a los niños a dar soluciones inimaginables por los adultos, a problemas de locotidiano; las emociones, que también son elementos que merecen consideración y permean el día a día de todos, componiéndolo. Lo aprendido en losdiferentes campos de conocimiento, está esparcido en la intensidad de lo cotidiano de guarderías y preescolares, cuyo formato escolar, que divide el conocimiento en áreas que poco o nada dialogan entre sí, de carácter excesivamente escolarizado, privilegiando el trabajo individual en detrimento del colectivo, deforma o restringe las ricas y vigorosas manifestaciones que se hacen sentir entre estos niños pequeños, en los espacios colectivos de educación y cuidado.

La experiencia descrita en este artículo, fue el motivopara la creación colectiva de un proyecto de estudios e investigación, en esa unidad escolar, concentrado en el conocimiento de la historia de la, en ese entonces, Escuela Municipal de Educación Infantil, conocida desde 1935 como Parque Infantil de Lapa. Este artículo tiene como objetivo relatar aspectos del proyecto y algunas de sus divisiones, que se centró, a partir delahistoria de los parques infantiles, en recuperar partes de la historia de la propiaEMEI.

El proyecto fue un punto que aglutinó diferentes discusiones, que incluían a los niños y demás profesionales de esa unidad escolar, sobre la importancia del conocimiento histórico en la primera infancia, y la gran dificultad de hacerlo, preocupándose también por la construcción de pertenencia al lugar y de culturas infantiles, debatidas y difundidas desde la creación de los parques infantiles, así como dar continuidad a la construcción de la historia personal de los niños, en el contexto histórico, social, cultural en el que estaban viviendo. Resalto que esta experiencia, junto con otras similares, vividas en diferentes contextos, contribuirá con una perspectiva de investigación en la que los conocimientos históricos, en diálogo con los estudios sociológicos y antropológicos, puedan ayudar a entender la niñez en diferentes contextos, así como pensar en el trabajo que considere los estudios enfocados en la enseñanza de la historia,para niños pequeños, sin vulnerar las características propias de la primera infancia, en lo que respecta a la construcción de conocimiento, la imaginación, fantasía, tan peculiares y fundamentales en la primera etapa de la educación básica.

Se espera mostrar aquí, aunque brevemente, una imagen organizaday no exhaustiva de la experiencia que reunió niños y adultos, de todos los segmentos pertenecientes a la EMEI Neide Guzzi de Chiacchio, el antiguo parque infantil, en el curso de un proyecto que optó por partir de la escucha y la observación atentas de aquello que los niños y niñas mostraban como deseos y curiosidades, lo que fue 
fundamental para el camino que se siguió. La opción por el trabajo con proyectos de larga duración, que define los caminos de formación de todos los involucrados, se debe al reconocimiento de la importancia de que los niños construyan redes de significaciones. El rumbo tomado rompió con los estudios que buscan simplemente el reconocimiento de contenidos y hechos históricos, que tantas veces redundan en ejercicios sin sentido para sus participantes. Se partió considerando a los niños como autores e inventores.

Se optó incluso por el acercamiento a los juegos, bailes, canciones y dibujos como manifestaciones artísticas que pueden ser experimentadas por todos, las cuales fueron conocidas a partir de las fuentes documentales encontradas por las profesoras y por los niños, en la propia EMEI, en visitas al Departamento del Patrimonio Histórico o incluso en la Cinemateca de Sao Paulo y el Instituto de Estudios Brasileros de la USP (Universidad de Sao Paulo). Se trataba de pautas musicales, dibujos de niños entre los años 1935 y 1938 y la fotografía de Benedito Junqueira Duarte, reproducida del original, canciones de la época y actuales, el cuaderno de una de las profesoras que actuó en 1950. A lo largo del proceso se aprendió, entre otras cosas, que los estudios históricos y aquellos centrados en la enseñanza de la historia, al valorar el contacto de los niños con fuentes de investigación, favorecen la construcción del conocimiento histórico. No se trató de un proyecto cerrado, sino de algo que se fue construyendo en el tiempo y a partir de la curiosidad y los descubrimientos de las profesoras y los niños, destacando que existió el privilegio de una inclusión de todos los profesionales de todas las secciones pertenecientes a esa unidad educativa.

\section{El proyecto o conocer la historia con los niños y niñas}

Las preocupaciones frecuentes entre las profesoras se convertían en compromisos con las singularidades de la primera infancia y sus características en esta etapa de la educación básica. Los desafíos enfrentados se orientabana la naturaleza de la historia para ser abordada con los niños má spequeños, al mismo tiempo en que se pensaba "cómo hacer" tal trabajo. Se sabe, como afirma Bittencourt (2007), que la enseñanza de la disciplina escolar historia a veces presenta obstáculos, para algunos insuperables, entre los niños en esta edad pues según cierta lectura piagetiana, tal perspectiva de trabajo es considerada imposible, ya que entre los niños de esta edad, no habría condiciones para el aprendizaje de los conceptos esenciales para el estudio de la historia y, particularmente, la noción de tiempo histórico.

Esta perspectiva, en principio, haría imposible cualquier trabajo de estudio e investigación que indague sobre el conocimiento histórico con niños. Aún más, esa visión no toma en cuenta a los niños y niñas como sujetos en el proceso de construcción de conocimientos y de la propia historia. Se puede percibir tal perspectiva como reveladora de una concepción de la infancia como "vaso vacío" (MOSS, 2003), en espera de los conocimientos que serían transmitidos por los 
adultos, reconocidos como los legítimos transmisores de los saberes. Sin embargo, tal como nos proponen Corsaro (2009) y Florestan Fernandes (1946), lo que tenemos es una capacidad enorme de aprendizaje y construcción de culturas infantiles, en la relación entre sujetos de edades iguales y diferentes o de barrio, que se constituye de diversas maneras, variando de acuerdo con los contextos sociales, históricos, culturales y económicos en los cuales los niños se encuentran. Se puede inferir que no se trata de términos exclusivos de la educación media o primaria, pero debe preocuparnos la manera en que concebimos la relación de los los niños con los diferentes campos del conocimiento. Hay que subrayar aquí que es el resultado de múltiples relaciones lógicas, afectivas, sensoriales, cognitivas, no siendo un conjunto estable, jerárquico, lineal.

Las profesoras, junto a los demás profesionales de la unidad escolar, no se preocuparon por la madurez biológica de los niños, en una percepción etapista del desarrollo infantil, sino tomaron en cuenta aquello que traían como conocimiento y experiencias desde muy pequeños, antes de llegar a la escuela, en la relación con los otros, en una demostración de respeto y reflexión profunda sobre aquello que los niños son: alguien que, a pesar de la poca edad, posee experiencias históricas que no pueden ser dejadas de lado en las planeaciones, en la organización del espacio físico, en la elección de los materiales utilizados, en prácticas educativas que prescinden de las evaluaciones como manera de medir los contenidos y el aprendizaje, al mismo tiempo que considera a los niños integralmente.

La observación de lo que los niños deseaban y hacían, exteriorizado, de forma explícita o no, era un punto fundamental para las profesoras, servía como luz para orientar el trabajo y, todavía más importante, el proceso, y no solamente su resultado. Se trata, como afirma Benzina,

De un instrumento funcional y privilegiado que puede ser considerado como forma de exploración de los contextos, que debe ser utilizada en la articulación de los proyectos de investigación, recogiendo de forma organizada los aspectos significativos de una situación. Es escoger qué observar, cómo observar y qué significado, cuáles valores atribuir a las informaciones conquistadas. (2001, pp. 47, traducción del autor).

Como ya afirmamos, el inicio de este proyecto se dio cuando los niños fueron descubriendo, aleatoriamente, fragmentos de baldosas en el parque de la EMEI, sirviéndose de ellas como objetos de juego. Los pedazos de baldosas eran, evidentemente, objetos de cultural material que sirvieron como mediadores para las discusiones con los niños, dotados de memoria histórica, pues reflejaban, en cierta medida, el modo de pensar y actuar en la educación infantil de determinado periodo. De esta manera, no se trataba solamente de "pedazos", sino de elementos constituyentes de ambientes de determinado grupo social. Este descubrimiento, sin embargo, es coherentecon las aspiraciones de algunas de las profesoras, interesadas 
en conocer más y mejor la historia de la EMEI Neide Guzzi, desde su idealización, por Mario de Andrade, y su inauguración, en 1935, como Parque Infantil de Lapa. En el desarrollo del proyecto, preocupadas por el origen del parque infantil y sus transformaciones hasta la forma como se encuentra hoy, se volvió, entre otros temas, a la historia de la infancia de los niños parqueanos de ayer y que constituyó parte de la historia de los que hoy frecuentan la EMEI. Se fue mostrando, a lo largo del tiempo, un itinerario que se realizaba en la escuela y asumía significados para los involucrados, recordado, examinado, analizado, en sus más diversas posibilidades, reconstituido y socializado entre todos. Resalto que el proyecto ganaba, cada vez más, nuevas proporciones y contribuciones de recuerdos y fuentes documentales que colaboraban para estimular y justificar el proyecto propio.

La preocupación pedagógica, junto con la construcción del conocimiento histórico, hacía visibles, también por la documentación, fuentes que, al ser investigadas, revelaban aspectos de los parques infantiles, y mostraban el proceso por el cual pasaban los niños. Se utilizaban entrevistas con antiguos alumnos ${ }^{4}$, conversaciones libres con los niños, fotografías tomadas en abundancia, siendo utilizadas en la época como puntos de conversación para discutir el camino seguido y, al mismo tiempo, registrarlo, y discusiones a partir de reproducciones de fotografía tomadas de los parques infantiles por el fotógrafo Benedito Junqueira Duarte. Las documentaciones producidas por los niños, y recolectadas continuamente, les permitían que tomaran contacto con los descubrimientos y conquistas propias, posibilitaban que se reflexionara sobre el itinerario recorrido y el que estaba por venir, lo que garantizaba una toma de posición, al tener que decidir qué rumbos tomar en el ámbito de las investigaciones que serían emprendidas. De esta manera, la documentación histórica dialogaba con la documentación pedagógica que iba constituyéndosey volviéndose representación de historias construidas por las profesoras y los niños.

Fotografías, canciones y cuaderno de apuntes de una exprofesora de los años de $1950^{5}$ se constituyeron como fuentes invaluables para orientar las investigaciones, suscitar curiosidades y garantizar la existencia del levantamiento de cada vez más hipótesis y confrontaciones con los resultados, aunque provisionales. Un verdadero clima de investigación que invadía a todos, sin excepción, al considerar aquí la

4 En las limitaciones de este artículo, estas entrevistas no serán privilegiadas, pero, resalto el trabajo vigoroso realizado por Mayra Villella Gallatti Ozzetti, directora de la EMEI, de recolección de entrevistas, las que, posteriormente fueron compiladas en un video. Vale la pena destacar que, durante la investigación, la alumna "número uno" matriculada en el Parque Infantil de Lapa fue encontrada y participó de algunos encuentros y festejos que ocurrieron en la EMEI, a lo largo de ese año.

5 Es interesante observar que si lo que se encontró motivaba los descubrimietos entre los niños, el cuaderno de la antigua profesora fue un importante incentivo para las profesoras, para que reflexionaran e investigaran sus prácticas educativas actuales, en relación a aquellas desarrolladas décadas atrás, incluyendo formas de corrección, actividades propuestas, formas de escritura e incluso la manera de organizar el cuaderno de registros. 
participación de los profesionales operativos que atendían la escuela. El hilo conductor era creer que lo esencial era dar importancia a las experiencias directas de contacto con la historia de los parques infantiles y, hoy, de la EMEI, en una perspectiva de historia del presente de los niños y adultos, mediante las discusiones basadas en las fuentes y demás materiales encontrados, valorando las propuestas e iniciativas de los niños y niñas, en conjunción con los caminos que también eran sugeridos por las mujeres que trabajaban en el lugar.

Los ya mencionados fragmentos de baldosas encontrados en el parque de la EMEI sirvieron, por lo mismo, como pistas para indicar lo que había en aquel espacio. Inmersas en el deseo de resolver estos aspectos de aquella historia y exponerla como fundamental, para que todos la conocieran, las profesoras movilizadas también salían a buscar de dónde provenían los restos. Con la observación de las fotos, pronto la incógnita sobre los fragmentos de baldosas fue descifrada. Pero, ¿de dónde provenían? Tales pedazos comenzaron a mostrar lo que había quedado de la piscina amplia que quedaba en aquel espacio, y que fue rellenada cuando los parques infantiles pasaron a ser las actuales Escuelas de Educación Infantil, las cuales ganaron una fachada arquitectónica de carácter más escolar, con salones de clase y disminución de los espacios destinados a los juegos.

"Lo que más nos gustaba era la piscina. Ish! Tirábamos tinta en el agua para verla cambiar de color. Estábamos preparados para las profesoras" ${ }^{\prime 6}$. (Testimonio de uno de los primeros que frecuentaron el Parque Infantil de Lapa, recopilado por Mayra Villela Galatti Ozzetti - directora de la EMEI).

Esa piscina era un lugar de ejercicios, lo que era común en los parques infantiles, pero más que eso, como puede ser percibido en el testimonio de uno de los que la frecuentaban, hoy ya fallecido, era un espacio de cultivo de juegos y experiencias variadas, de escapatorias de los niños y exposición de sus invenciones. Las fotografías encontradas por las profesoras, demostraban la presencia de los niños de otros tiempos, disfrutando de ese espacio, que al ser enterrado, fue sustraído de los niños que hoy frecuentan la escuela, como lugar de convivencia, exploración y creación. Los pedazos de baldosa, restos de piscina, evidenciaban una preocupación por los niños que contradice gran parte de las concepciones actuales sobre los niños de la primera infancia, provocaron que se pensara sobre el derecho al juego en otros ambientes, tales como el agua, que privilegian diferentes descubrimientos en, como eran Ilamados en la época, tanques de recreación, lugares en los que el tiempo acelerado fuera superado por el tiempo de los descubrimientos, andando sin preocupaciones...

6 Hay ciertas expresiones propias del portugués oral, que son imposibles de traducir a español. A continuación, dejamos el testimonio original en portugués para su consulta: "O que nós mais gostava (sic) era da piscina. Ih! nós jogava tinta na água para ver ela mudar de cor. Nós aprontava com as professoras". 
Los niños indignaban constantemente y se preguntaban: ¿si había piscina, por qué ya no existía? Este cuestionamiento frecuente, hacía que las profesoras trabajaran con miras al proceso de transformaciones históricas, que tuvo como resultado una alteración profunda en el espacio físico de la escuela, lo que desembocó en modificaciones en las prácticas educativas, en las relaciones establecidas entre todos, en el tiempo dedicado al descubrimiento y al juego. Los niños y las niñas, sin darse cuenta, estaban debatiendo los primeros temas de la naturaleza histórica. El pasado, al hablar de un tiempo en que ni siquiera habían nacido, estaba presente en las preguntas y apuntaba a debates pertinentes sobre la actual constitución de aquel lugar y de los propios niños que frecuentan esa escuela de educación infantil. Teníamos, a partir de las niñas y los niños, una especie de reivindicación del tiempo para los juegos y las diferentes posibilidades de creación, que se ubican, indirectamente, opuestas a la silenciosa y sistemática exclusión de la dimensión de lo imprevisto, de los descubrimientos, tan preciados para los niños y que en otros tiempos se hacían más frecuentes, en un espacio más grande y rico en actividades enfocadas en su crecimiento.

\section{Entre las transformaciones históricas del parque infantil hacia EMEI Neide Guzzi}

Pero, ¿desde dónde estamos hablando? La actual EMEI, punto de partida del proyecto enfocado en el conocimiento histórico en la primera infancia, fue uno de los primerosparques infantiles pensados por Mario de Andrade e inaugurados en 1935, en la ciudad de Sao Paulo, bajo la gestión del alcalde Fabio Prado. Inicialmente, como ya hemos mencionado, fueron creados tres parques infantiles: Ipiranga, D. Pedro y Lapa, este último situado en el barrio de Lapa de Abajo, que mantuvieron algunas de las características originales que conviven con una organización espacial que se acerca a un formato escolar, con salones de clase y corredores ${ }^{7}$.

Algunas indagaciones sugirieron: ¿qué aspectos de este parque infantil, que figurarían entre los niños de otros tiempos, se encuentran aún presentes, qué ha permanecido igual? ¿Qué puede ser revelado a partir de las pistas encontradas por los niños? ¿Qué avances y retrocesos? ¿Qué rupturas y cambios? ¿Cuál es la contribución de los descubrimientos de los niños y adultos para el conocimiento histórico abordado en la primera infancia?, algo que exige una sensibilidad refinada y un conocimiento sobre las especificidades de los niños en esta edad. Llegó la hora

7 La sensibilidad de Mario de Andrade con la infancia se vincula a la expresión de una estética modernista quepresenta la temática de la infancia de modo genuino. Tal interés fue manifestado en artículos publicados en el Diario Nacional, donde colaboró como cronista y crítico de arte hasta que el periódico fue cerrado en 1932. Textos como Pintura Infantil (1930), Da criança prodígio I, II y III (1929), entre otros, fueron compilados en el libro Táxi: Crônicas no Diário Nacional. Se percibe en ellos, el delineamiento del concepto de niño como portador de culturas, ciudadano, múltiple en sus posibilidades de creación y de presencia en los diferentes espacios y relaciones sociales, de donde se destaca la discusión sobre arte y niñez. 
de detenernosun poco en los parques infantiles creados por Mario de Andrade, que en cierta medida, se constituían en el gran fundamento de los descubrimientos de todos en la actual EMEI y en el proyecto desarrollado.

Los parques infantiles, en el periodo de 1935, cuando fueron creados por Mario de Andrade, se constituían como expresión del interés en relación a la infancia hija de la clase trabajadora de Sao Paulo, en el rango de edad de 3 a 12 años, para la que estos parques y la educación extraescolar eran destinados. Las actividades se enfocaban en la integración del juego, la cultura, el arte, el conocimiento del folclor nacional y la salud de los niños, entre lo que merece ser resaltado. Inspiró fuertemente el proyecto con los niños en la EMEI, orientando las diferentes perspectivas en las que las manifestaciones artísticas se hacían presentes de forma constante. Subrayamos la importancia del diálogo entre artes y estudios de la historia, en este proyecto, aspectos que no habían sido tenidos en cuenta cuando entramos en contacto con las investigaciones centradas en la primera infancia, y encontramos las afirmaciones de que las diferentes manifestaciones artísticas deben componer los espacios destinados a la educación y al cuidado de los niños pequeños.

Danza, música, pintura, escultura, juegos entre adultos y niños estaban presentes. Las investigaciones de Mario de Andrade, como estudioso del folclor nacional, encontraban un lugar privilegiado para expandirse. En lo que respecta a las investigaciones folclóricas, todo el material compilado por Mario de Andrade en su viaje a la Amazonía, servía como base para dramatizaciones de los niños de los parques infantiles, en una búsqueda para regresar a la cultura nacional, tan alabada por los modernistas, conocida, construida y practicada por los niños y las niñas. Había en estos espacios físicos propuestos por Mario de Andrade, el arte como hilo que guiaban las creaciones infantiles, en un diálogo entre arte, educación y cultura, presentes en el día a día de los niños, donde se creaban entornos propios para ellos, conviviendo entre sí, en la mezcla de diferentes edades.

Tal perspectiva, que se remontaba a setenta años atrás, era recordada y problematizada por las profesoras algunas décadas después, no en una perspectiva de conservación de la historia, como si no fuera dinámica. Esta dimensión folclórica tuvo lugar en el proyecto, a partir del momento en que las copias de antiguas partituras de canciones y una pequeña ópera popular, descubierta por Mario de Andrade en sus viajes, fue encontraday abordada por los niños. Cabe citar que, inicialmente, el tipo de música no cayó inmediatamente en el gusto de los niños, que cuestionaban sobre el porqué de tanta diferencia sonora y musical, al mismo tiempo en que se fruncían las narices y algunos salían de los salones donde se proponía la escucha de las canciones.

Respecto a los parques infantiles, se percibe que se trataba de sacar a flote varias provocaciones innovadoras, de modo que se promoviera la creación, la invención, 
la expresión, la búsqueda de soluciones que, de forma colectiva o individual, se encuentran apoyadas en un territorio de la infancia y para la infancia, en el que las culturas infantiles sean construidas y reconocidas.

Una pregunta, entre tantas, resonaba entre las profesoras: ise ha pensado si podemos encontrar partes de esas marcas documentadas actualmente por nosotros hace décadas, revelando aspectos de una infancia que, en cada nueva mirada, puede revivir en nosotros y contribuir con nuestros conocimientos sobre ella misma? No se trata de una obsesión por la memoria, sino de considerar su importancia, lo que en cierta manera fue posible por los descubrimientos de los propios niños. Como afirma Benzoni (2001, p.54-55, Traducción del autor), "se trata de un trabajo que presenta la posibilidad de mantener los trazos de un trabajo, de no perder el sentido y conservar las memorias de las experiencias". La memoria, según esta autora, no es solamente un recuerdo, sino algo que nos marca como experiencia, marcando fuertemente nuestra identidad. Quien pasa por esta experiencia podrá, por medio de documentaciones, reencontrarla en el tempo, verla de nuevo a la distancia, de un modo crítico o desde un nuevo ángulo de diversos puntos de vista más maduros.

Cuando buscaban saber algo sobre los parques infantiles y, en especial el de Lapa, se encontraban con la perspectiva de un trabajo institucional que en la expresión del modernismo, se mostraba en la fusión entre sus preocupaciones estéticas e ideológicas, que se configuraban en el Departamento de Cultura del municipio de Sao Paulo y, sobretodo, en los parques infantiles, lo que permite demostrar que los principios de las propuestas renovadoras del modernismo brasilero estaban contemplados en su forma de crear la administración pública. Estas diferentes dimensiones permiten realizar diversos estudios y enfoquesvariados. Debido a esta presencia de la dimensión modernista en los parques infantiles, cabe estudiar aquello que puede ayudar con los avances de la educación infantil brasilera actualmente. En este punto, tal recorrido motivaba no solo a los niños, sino de modo concomitante, incentivaba a las profesoras que lo adoptaban para pensar su propia historia docente, las creencias y los valores en el campo de la educación.

La frecuencia de los niños en los parques infantiles, inicialmente, era libre y aquellos que eran alumnos de los Grupos Escolares, correspondientes a las actuales escuelas de Educación Fundamental,podrían participar de las actividades, en horarios alternos a los de las clases. Como afirma Faria (2002), se trata de los orígenes de la red pública de educación de la primera infancia en Sao Paulo.

Como está registrado en las solicitudes a las instructoras que trabajaban directamente con los niños en los parques infantiles, en el Acto n. 1146 de 4/7/1936, se propiciaban experiencias de diferentes modalidades, provocando la comprensión de la pertinencia de las actividades colectivas como forma de relación social, como construcción de estos sujetos de poca edad. De esta forma, asociando la práctica 
de la organización de clubes y periódicos a las de las producciones artísticas, destacando la creación de dibujos -tal como ocurría en el día a día de los parques infantiles-, lo que nos queda es la ruptura con los principios más tradicionales de organización del espacio y del acercamiento curricular para la Educación Infantil y las etapas iniciales de la Educación Fundamental, que se abría para la ciudad, la cual se urbanizaba en torno a los parques infantiles. El tener contacto con las propuestas presentadas para la formación de las instructoras -profesoras- que trabajaban en los parques infantiles terminó en debate sobre la actual formación de las docentes que trabajaban con niños en la EMEI. ¿Qué propuesta continuó? ¿Cuáles fueron los cambios? ¿Qué se podía aprender con las propuestas anteriores y y ha sido objeto de transformaciones, a lo largo de las décadas, en lo que respecta a las expectativas docentes? Eran preguntas que guiaban las conversaciones y lecturas que realizabanlas profesoras a lo largo del proyecto.

Mario de Andrade, aprehensivo con los rumbos de la educación, percibía originalmente la necesidad de prácticas educativas enfocadas en los niños de su propio tiempo, en un constante diálogo entre culturas, ciudad y manifestaciones artísticas. Vale resaltar que la perspectiva de un trabajo que conjugaba artes, folclor y demás manifestaciones humanas inspiró considerablemente la configuración de la EMEI y de las actividades realizadas actualmente.

Uno de los aspectos debatidos buscaba destacar algo que ya era importante décadas atrás. Es posible inferir, a partir de las exigencias constantes del Artículo 207 del Acto n. 1146, de 4/7/1936, que se trataba de algo que contemplaba ciertas experiencias prácticas entre aquellos que trabajarían con los niños, tales como "velar por el niño" "sin impedirle o amenazar la libertad y espontaneidad en el juego" o incluso, "enseñar la práctica de juegos infantiles, participando de las actividades lúdicas y recreativas".

En las actividades que se realizaban, tenían privilegio la dramatización de cuentos e historias, las canciones, el modelado, la carpintería, el baile, la música, sin olvidar la formación Normal, antiguo Magisterio, preferencialmente de la Escuela Normal Caetano de Campos. Entre lo que era comprendido como las propuestas educativas innovadoras de los parques infantiles, se encontraban las actividades lúdicas y algo que llamó la atención en extensas y fructíferas discusiones entre las profesoras: Mario de Andrade, en las solicitudes que hacía a las instructoras, les pedía que no hicieran anotaciones en los dibujos de los niños, afirmando que se trataba de una intervención en las creaciones infantiles. Fue curioso que las profesoras se dieran cuenta, hasta hoy, con la continuidad de esta práctica y discutían sobre el porqué de ella, por qué escribir sin la autorización del niño, entre otros aspectos.

Las prácticas educativas tenían continuidad también en las pequeñas exposiciones organizadas al interior de los parques infantiles, registradas en las fotos de Benedito 
Junqueira Duarte, trayendo la perspectiva de un ambiente-memoria, que aunque no tuviera como preocupación central los resultados de lo que fuera producido, traía la posibilidad de que aquellos que circularan en los parques infantiles, entraran en contacto con lo que era producido ahí adentro, valorizándolo, cuestionándolo, observando y aprendiendo con las marcas dejadas por los niños. Se trata de documentar no solamente los resultados, sino los procesos. Con esto, se narraba lo que pasó, de manera compuesta por escritos, imágenes, objetos, que revelan la presencia de los niños hasta en su ausencia.

Tales exposiciones ganaron un espacio grande también en la EMEI, cuando no se buscaba crear un espectáculo con las creaciones infantiles, sino destinar una mayor cantidad de tiempo para observarlas y conocerlas y con esto, aprender sobre la propia infancia.

\section{En los parques infantiles y en la EMEI: Ios dibujos como documentos históricos y como expresión infantil}

Una de las actividades frecuentes en las escuelas de educacióninfantil es la creación de dibujos. sin embargo, en el desarrollo de este proyecto, tal práctica no convencional ganó otros aires, inspirados por la propia historia con la que todos venían tomando contacto. Se trata del trabajo con dibujos a partir de conversaciones y relaciones establecidas entre aquellos creados por los niños entre 1935 y 1938, y los dibujos de ahora, de los niños y las niñas de la EMEI.

Mario de Andrade, en una de sus facetaspoco exploradas, mostraba interés por las creaciones de dibujo de los niños y jóvenes, coleccionándolos y reflexionando profundamente sobre esta manifestación infantil. Esteconocimiento generó pesquisas investigaciones para conocer a profundidad lo que pensabaacercadel asunto. En la concepción de Mario de Andrade acerca dela niñez, no había nadamejor que hacer público lo que los niños creaban, guardar para observar, para ser vistos como constructores, y no solo como consumidores de cultura: los dibujos podrían saltar los muros de las escuelas, entrar en los barrios, la ciudad, volviéndose visibles para todos los que quisieran apreciarlos, fuera de un espacio escolar que tantas veces cae en una perspectiva de confinamiento. Esta experiencia fue propuesta en la creación del mural que queda en la parte externa de la EMEI, los dibujos creados por los niños eran reproducidos y recreados en las baldosas y allí se encuentran hasta hoy. Su importancia, entre otras cosas, encuentra resonancia en la propuesta de documentar la presencia y las marcas dejadas por los niños en la historia, que como sabemos, no se ve ni se considera.

Entre los dibujos creados en los parques infantiles y mostrados a los niños, los temas muchas veces se repetían, las flores aparecen con cierta recurrencia y presentan, como característica más frecuente, ramitas. Según las observaciones de 
Mario de Andrade sobre este conjunto de dibujos: "las flores y los frutos son de preferencia casi exclusiva de las niñas, como tema. No hay ni un solo caso de solo flores, dibujadas por niños. Las frutas rara vez aparecieron solas. En general, solo las representan como complemento de árboles" (1996). Es interesante detenernos en uno de los dibujos, representativo de los demás, y pensar en las transformaciones temáticas, de trazos, formas y colores que se encuentran en los dibujos actuales. Esta preocupación ocupó parte del proyecto desarrollado en la EMEI, cuando una de las profesoras se encargó de mostrar a los niños qué y cómo los niños que asistían al antiguo Parque Infantil de Lapa creaban en sus dibujos.

La inscripción: "fue respetada la expresión del niño en lo que dijo o hizo", encontrada en el reverso de los dibujos, aparece en los trabajos hechos por niños dehasta seis años, lo que nos permite pensar en una atención mayor en relación a su expresión, considerada "más libre", en una actitud de valorización estética de la producción y, en consecuencia de la propia niñez de los dibujantes.

\section{6. Últimas palabras, por ahora...}

En este artículo, se buscó presentar los elementos de un proyecto desarrollado en la Escuela Municipal de Educación Infantil Neide Guzzi de Chiacchio, que tuvo como propósito trabajar con el conocimiento histórico entre los niños pequeños, como ya mencionamos, se trató de un gran desafío. Algo que fue aprendido en el transcurso de este proyecto, fue a alimentarse de las propias propuestas que iniciaron los parques infantiles, pero sin ubicarlas en un lugar incuestionable, cristalizado o incluso comparándolas con lo que ocurrió décadas atrás. Aquello que se conservó en las actuales propuestas, incluso educativas, era problematizado, en un proceso de intensa ruptura con el pasado, en una comprensión de que este no se reduce a apenas algunos hechos elegidos como oficiales, en pocas palabras, el pasado servía para pensar el presente junto a los niños.

La valorizacióndel niño fue una constante y siempre fue sujeta a reflexiones, con esto sus creaciones fueron potencializadas, la imaginación y la invención estuvieron presentes en cada día, creando una apreciación estética del mundo, que también es creado y recreado por los niños, para ellos y con ellos. Partiendo de esta premisa, las profesoras de la EMEI fueron percibiendo, en los descubrimientos hechos por los niños, una gran motivación para el inicio de caminos y encuentros del conocimiento histórico junto a los pequeños.

Tanto en el proyecto de la escuela, enfocado también en el conocimiento histórico, como en las propuestas de los parques infantiles, el dibujo, el juego, todas las formas de expresión de los niños estuvieron presentes de forma recurrente. Por esta razón, el placer de los descubrimientos y las elaboraciones eran muy comunes y se constituyeron como prácticas que no cohibian ni a niños, ni a adultos, al transformar su cotidianidad en anticipación de la escolarización, que es cercada por muros 
invisibles, y que se vuelven muy claros cuando percibimos que el conocimiento se fragmenta en áreas que poco o nada dialogan entre sí. Las marcas de la ansiedad por el mañana aparecen cuando en el día a día de los niños solo hay espacio para el desarrollo de actividades ya preparadas- ¿o "pre-paradas?, que consisten en año tras año, seguir un "desarrrollo" de lo simple a lo más complejo, de lo pequeño a lo grande, de lo concreto a lo abstracto, revelando que cada fase de la vida del niño en la escuela está en función de los momentos sucesivos de lasuperación de pasos previstos, que tienen como objetivo grados más elevados, sin tomar en cuenta al niño mismo. Como afirmara Staccioli (2002, p. 5):

Se debe sustituir el ansia por el mañana por la riqueza del hoy, al acoger el presente (con todas las sorpresas, contradicciones que este implica) sin dejar de trazar el futuro; mirar la infancia ahora y no como algo que dará frutos mañana; observar sus capacidades de innovar que enriquecen también a los adultos.

No se trata de dejar de lado aspectos relacionados con las áreas de conocimiento que serán trabajadas al interior de las escuelas de educación infantil, esta preocupación requiere que las miradas estén atentas, sean problematizadoras, capaces de cultivar en los niños, en el sentido explícito y también implícito, informaciones para construir una jornada de trabajo coherente, para organizar mejor el espacio y el tiempo, al dar forma a las creaciones, a la exuberancia de los niños, de sus proyectos, considerando su diversidad y, como afirma Kuhlmann Jr., "practicando orientaciones curriculares que estén pautadas por la simplicidad, en lugar de formular una complejidad simplista" (1999, p. 58).

De allí que el hecho de estar con los niños y aprender con ellos y a partir de ellos, se vuelva fundamental. La especifidad de esta profesión reside en esto y en la necesidad de investigación constante sobre los niños, sus emociones ysu deseos de aprender. Para esto, aliar los campos teóricos, tales como los conocimientos que fueron y que están siendo producidos sobre la niñez y las áreas que la estudian, con los campos de la práctica educativa es fundamental. Citando a Kuhlmann Jr (1999, p. 65):

Pero tomar el niño como punto de partida exigía comprender que para él conocer el mundo involucra el afecto, el placer, el no placer, la fantasía, el juego y el movimiento, la poesía, las ciencias, las artes plásticas y dramáticas, el lenguaje, la música y la matemática. Que para el niño el juego es una forma de lenguaje y el lenguaje, una forma de juego.

Retomando la cita inicial de este artículo, la gran ventaja en este estudio de historia se centra en la posibilidad de comprender, de modo más articulado, lo que sucedió hasta hoy. Se buscó realizar esto con los niños más pequeños, una tarea ardua, desafiante y no menos importante en la consitución de esos niños y niñas y, por qué no, de los profesionales involucrados. Sabiendo que no se puede volver atrás y convertir los Parques en un lugar idílico para la infancia, se puede a partir de 
esto, construir otros proyectos que aun seestán disociados en festividades, estudios (diseños, ilustraciones), videos y nuevas investigaciones. Aquí no se trató de volver a una historia factual, preocupada con el estudio tan debatido, sobre el llamado patrono de la escuela, pero sí de cuestionara partir de la propia unidad escolar enfocada en la educación de la primera infancia, cuáles son las posibilidades de trabajar el conocimiento históricocon los niños más pequeños. Esta fue una de las preguntas que iban surgiendo y haciéndose en la construcción del propio proyecto, al mismo tiempo que los conocimientos ya acumulados sobre la primera infancia, a partir de incontables trabajos y lecturas realizadas, dialogaban constantemente en una actitud vigorosa. 


\section{Bibliografía}

Andrade, M. (1967). Aspectos das artes plásticas no Brasil. São Paulo: Martins Fontes.

Andrade, M. Depoimentos 2 - publicação periódica para debate de arquitetura Centro de Estudos Brasileiros/ GFAU, s/d [mimeo]

Andrade, M. (1992).Será o Benedito? Crônicas do suplemento em retrogravura do Estado de São Paulo. São Paulo: EDUC.

Andrade, M. (1976).Táxi e crônicas do diário nacional. São Paulo: Livraria duas Cidades.

Andrade, M. (1986). A escrava que não é Isaura. EnAndrade, M. Obra imatura. São Paulo: Martins Fontes.

Andrade, M. (1975).O baile das quatro artes. São Paulo: Martins Fontes.

Andrade, M. (1975).Quatro pessoas. Belo Horizonte: Itatiaia.

Andrade, M. (1971). Do Desenho. En Andrade, M. O desenho de Lasar Segall. São Paulo: Museu Lasar Segall.

Andrade, M. (1988).Cartas a Murilo Miranda (1934-1945). São Paulo: Nova Fronteira.

Andrade, M. (1982).Cartas a Oneyda Alvarenga. São Paulo: Duas Cidades.

Andrade, M. (1981). Cartas de trabalho: correspondência con Rodrigo Mello Franco (19361945). Brasília: MEC/SPHAN, 1981.

Andrade, M. (1988).Pintura e Assunto. O Estado de S.Paulo. 13/4/41. EnMAC-IEB, Catálogo da Exposição comemorativa dos 25 anos do MAC e do IEB.

Andrade, M. (1988). As escapatórias do Amor. O Estado de S.Paulo. 16/4/41. EnMAC-IEB. Catálogo da exposição comemorativa dos 25 anos do MAC e do IEB.

Andrade, M. (1963).Cai, cai, balão. En Andrade, M. Os filhos da Candinha. São Paulo: Martins Fontes, pp. 123-126.

Andrade, M. (1966). $6^{\text {a }}$ aula. O primitivo e a criança. Centro de Estudos Brasileiros. Depoimentos. p 6776, 1966.

Andrade, M. (1972). Divina Preguiça. En RossettuB.et al. Brasil, primeiro tempo modernista. 1917-1919. São Paulo: IEB, pp. 181-183.

Andrade, M. (1972). Uma grande inocência. EnAndrade, M. O empalhador de passarinhos. São Paulo: Martins Fontes.

Andrade, M. (1939). Piá, não sofre, sofre? EnAndrade, M. Os Contos de Belazarte. São Paulo: Martins Fontes.

Andrade, M. (1939). Tempo de Camisolinha. EnAndrade, M. Contos Novos. São Paulo: Martins Fontes.

Andrade, M. (1939). Primeiro de maio. EnAndrade, M. Contos Novos. São Paulo: Martins Fontes. 
Andrade, M. (1976). O pai do gênio. EnAnconaL.(Org.) Táxi e crônicas no Diário Nacional. São Paulo: Duas cidades, pp. 276-279.

Andrade, M. (1976). Da criança prodígio I e II. EnAncona L. (Org.) Táxi e crônicas no Diário Nacional. São Paulo: Duas cidades, pp. 129-134.

Andrade, M. (1976). Da criança prodígio III. En: Ancona L.(Org.) Táxi e crônicas no Diário Nacional. São Paulo: Duas Cidades, pp. 137-138.

Andrade, M. (1976). Pintura Infantil. EnAncona L. (Org.) Táxi e crônicas no Diário Nacional. São Paulo: Duas cidades, pp. 277-279.

Andrade, M. (1975). Do desenho. EnAndrade, M. Aspectos das artes plásticas no Brasil. Belo Horizonte: Itatiaia, pp. 71-77.

Andrade, M. (1976). Da criança prodígio III. EnAncona L.(Org.) Táxi e crônicas no Diário Nacional. São Paulo: Duas cidades, pp. 277-279.

Andrade, M. (1974). O movimento modernista. EnAndrade, M. Aspectos da literatura brasileira. São Paulo: Martins Fontes.

Becchi, E. (2003). Por uma pedagogia do bom gosto. EnBecchi, E. Avaliando a pré-escola: uma trajetória de formação de professoras. São Paulo: Autores Associados.

Benzoni, I. (2001). Documentare?Si, grazie. Bologna. Italia: Junior.

Benjamin, W. (1993).Obras escolhidas: magia e técnica, arte e política. São Paulo: Brasiliense.

Bittercourt, C. (2007). Fundamentos do ensino de História. São Paulo: Cortez.

Caruso, C.,Bonito, Â. (2002). Anita Malfatti: crianças famosas. São Paulo: Callis.

Corsaro, W. (2009). Reprodução interpretativa e cultura de pares. EnMuller, F.(Org.) Teoria e prática na pesquisa con crianças: diálogos con William Corsaro. São Paulo: Cortez.

Departamento de cultura. Regimento interno dos Parques Infantis. S/d.

Fernandes, F. (1979). A cultura infantil. EnFernandes, F. Folclore e mudança social na cidade de São Paulo. Río de Janeiro: Vozes.

Gallardini, A. (2002). Casa, scuola, museo: familiaritá, dissonanza nell'esperienza dei bambini. EnGallardini, A. Il Bambino con arte nellmuseo. ComunediPistóia: Junior, pp. 19-29.

Ginszburg, C. (2001).Mitos, emblemas e sinais: morfologia e história. São Paulo: Companhia das Letras.

Gobbi, M.,Leite, M. (2002). O desenho da criança pequena: distintas abordagens na produção acadêmica em diálogo con a educação. EnLeite, M.(Org.).Ata e desata. Partilhando uma experiência de formação continuada. Río de Janeiro: Ravil, pp. 93-148.

Gobbi, M. (1997).Lápis vermelho é de mulherzinha: desenho infantil, relações de gênero e educação infantil. Dissertação (Mestrado). Unicamp, Facultad de Educación.

Gobbi, M. (2002). Desenho infantil e oralidade: instrumentos de pesquisa concrianças pequenas. EnDemartini, Z.,Prado, P., Faria. A. (Orgs.) Por uma Cultura da Infância: por uma metodologia de pesquisa con crianças. Campinas: Autores Associados. 
Gobbi, M. (mayo-agosto 2002). Crianças nos parques: imagens de infância. Revista Proposições, 13(2): pp. 143159.

Kossovitch, E. (1990).Mario de Andrade plural. 2 ed. Campinas: Unicamp.

Kuhlmann, M. (1991). Instituições pré-escolares assistencialistas no Brasil (1899-1922). Cadernos de Pesquisa. 78: pp. 17-26.

Maviglia, M.,Zunino, G. (2002).Comunicazionegráfico-pittorica: itinerarididatticidiespressione e creativitáconmessaggi, forme e media. Bologna: Junior.

Mignola, L. (2001). La ompostazione della ricerca. EnMignola, L. Documentare? Sì, grazie. Bologna: Junior.

MAC-USP/ IEB-USP. (1997).Mario de Andrade e a criança. EnBarbosa, A. Leituras no sub-solo. São Paulo: Cortez.

Mallaguzzi, L. (1999). Entrevista dada a Giordana Rabitti. EnRabitti, G. Em busca da dimensão perdida. São Paulo: Artmed.

Mallaguzzi, L. (1996). Apresentação. EnMallaguzzi, L. I picolissimi Del cinema muto. Giochidifinsioni al nidofrapesci e Bambini. Comune de Reggio, 1996.

Mantovani, S. (1998).(Org.) Nostalgia do futuro: liberaresperanze per uma nuova cultura dell'infanzia. Bergamo: Junior, 1998.

Marin, L. (1996). Ler um quadro. Uma carta de Poussin em 1639. EnChartier, R.(Org.). Práticas da leitura. São Paulo: Liberdade.

Martins, C. (1992).Não sei desenhar. Dissertação (Mestrado). São Paulo, USP-ECA.

Moss, P. (2003).Qualidade na educação da primeira infância. Porto Alegre: Artmed.

Faria, A.,Demartini, Z.,Prado, P. (Orgs.). (2002).Por uma Cultura da Infância: por uma metodologia de pesquisa con crianças. Campinas: Autores Associados.

Prefeitura municipal de são paulo. (1993).A visão dos educandos. Movimento de reorientação curricular.

Rabbit, G. (1999).Em busca da dimensão perdida. Porto Alegre: Artmed.

Read, H.(1976).O sentido da arte. São Paulo: Ibrasa.

Read, H. (1986).A redenção do robo: meu encontro con a educação através da arte. São Paulo: Summus.

Scuolagirotondo. (1990-91). ScuolacomunalleDell'infanziaGulliver. Uguali i diversi:lêdiferen zesessualineipensieri dei bambini. Reggio-Emilia.

Staccioli, G. (2002).Immaginefatte ad arte: idéeedesperienze per educareallacomunicazionevisiva. Roma: Carocci.

Staccioli, G. (Nov. 1996). Disegnare per crescere. Bambini. XII(0).

Staccioli, G. (2002). Per uma educazione artística di senso. En Staccioli, G. Il Bambino con Arte nel museo. Comune di Pistoia: Junior. 